\title{
A experiência norte-americana com o seguro agrícola: lições ao Brasil?
}

\author{
Marcelo Fernandes Guimarães ${ }^{1}$ \\ Jorge Madeira Nogueira ${ }^{2}$
}

Resumo: O seguro agrícola é um instrumento eficaz de gestão de riscos rurais. Paradoxalmente, sua utilização pelos agricultores é relativamente reduzida em quase todo o mundo. Uma notória exceção é os Estados Unidos da América, país onde essa modalidade alcançou reconhecido sucesso. O processo, porém, foi lento, muito dispendioso e envolveu a participação determinante do Estado em diversas ações complementares. Dessa forma, países que desejam incluir esse instrumento dentre as prioridades de sua política agrícola, como parece ser o caso brasileiro, devem estar atentos aos requisitos para o seu sucesso e aos resultados e problemas gerados ou ampliados por sua massificação. O estudo da experiência norte-americana fornece lições relevantes.

Palavras-chaves: Gestão de riscos rurais, seguro agrícola, política agrícola norte-americana.

\section{Classificação JEL: Q18, Q12}

\begin{abstract}
Agricultural insurance is considered to be an effective to manage rural risks. Surprisingly, its adoption by farmers is very limited all over the world. An outstanding exception is the United States of America, country in which this

${ }^{1}$ Economista. Mestre em Agronegócios pela Universidade de Brasília.

2 Professor Titular, Departamento de Economia da Universidade de Brasília (ECO/UnB) e professor do Mestrado em Agronegócios da UnB.
\end{abstract}


- A experiência norte-americana com o seguro agrícola: lições ao Brasil?

instrument has achieved remarkable success. Nevertheless, the process of diffusion of agricultural insurance in the USA was slow and expensive. It has also required significant government intervention through a variety of complementary actions. In this context, countries willing to introduce this instrument among other agricultural policy tools, as it seems the case of Brazil, should proceed with caution. Agricultural insurance success has important pre-requisites and its general diffusion may amplify its problems. The analysis of the North American experience provides worthwhile lessons.

Key words: rural risk management, agricultural insurance, North American agricultural policies.

JEL Classification: Q18, Q12

\section{Introdução}

Em dezembro de 2003, o Congresso Nacional do Brasil aprovou a Lei no 10.823 que autorizou a concessão de subvenção econômica ao prêmio do seguro rural, regulamentada pelo Decreto no 5.121/04. Essa iniciativa partiu do executivo federal, interessado em estimular a incorporação dos seguros agrícolas aos instrumentos de suas políticas agrícolas, tendência também observada em diversos países. Mas, é importante conhecer um pouco mais da experiência de alguns países com o seguro agrícola para que se possa avaliar os prováveis resultados da política brasileira. Entre várias experiências existentes, este trabalho realiza uma análise crítica da experiência norte-americana com o seguro agrícola, a mais antiga de todas. Ao assim proceder, o texto aborda, ainda, parte do referencial teórico que dá sustentação a essa questão no âmbito da teoria microeconômica.

Os Estados Unidos da América (EUA) vêm desenvolvendo de forma sistemática medidas de apoio a esse instrumento desde a década de 1930. Não surpreende, portanto, que naquele país o seguro agrícola se encontre mais difundido. No entanto, foi somente a partir de meados da década de 1990 que a área segurada passou a representar uma parcela significativa da área cultivada e o seguro foi definitivamente incorporado à política agrícola norte-americana. Deve-se ressaltar, contudo, que este nível de desenvolvimento só foi alcançado devido ao papel extremamente ativo desempenhado pelo executivo dos EUA. Essa atuação envolveu gastos 
muito elevados de subsídios ao prêmio e às despesas operacionais e administrativas de seguradoras, além de diversas outras ações de apoio ao programa, inclusive resseguro.

Este artigo está estruturado em quatro seções centrais, que são complementadas por esta introdução e pela conclusão. Na próxima seção, as características gerais do seguro agrícola são brevemente analisadas. A terceira parte do texto é dedicada a apresentar os conceitos analíticos básicos que serão utilizados durante todo o estudo. As características da experiência norte-americana são descritas na quarta seção do artigo. Essas características são avaliadas criticamente na sua última seção, por meio de uma revisão de literatura científica.

\section{O seguro agrícola como instrumento de gestão de riscos}

A agricultura é uma atividade de elevado risco e significativa incerteza. Esses riscos e incertezas decorrem tanto da instabilidade de origem climática e das ameaças sanitárias, quanto das oscilações do mercado. Uma adequada gestão de riscos agrícolas pode afetar positivamente a estabilidade da renda do produtor rural e garantir sua própria permanência na atividade. No entanto, essa gestão mostra-se complexa, exigindo, dentre outros, boa capacidade gerencial e elevado conhecimento tecnológico, além de um alto nível de informações permanentemente atualizadas.

O gerenciamento de riscos no setor rural pode se dar de diversas formas. As mais comuns são a utilização de instrumentos oferecidos pelo setor de seguros e pelo mercado financeiro (mercados futuros, de opções, contratos a termo, etc.), a troca de insumos por produtos, a diversificação da produção entre diferentes culturas e criações e a diversificação de atividades dentro e fora do setor agropecuário. Dentre esses, o seguro agrícola é reconhecidamente um importante mecanismo de proteção da renda do produtor rural.

O seguro agrícola atua de forma a amenizar os riscos de perdas na atividade agropecuária e proporciona a recuperação de sua capacidade financeira na eventualidade de sinistros ocorridos por motivos naturais incontroláveis. O seguro representa, então, um instrumento eficaz para a transferência do risco da agricultura para outros agentes e setores 
econômicos (OSAKI, 2005 e AZEVEDO-FILHO, 2000). Adicionalmente, o seguro agrícola tende a estimular o aumento da área cultivada e a proporcionar uma garantia do fluxo de renda, facilitando assim a oferta de financiamento à atividade agropecuária.

Apesar dessas vantagens, esse instrumento tem tido muitas dificuldades para se mostrar economicamente viável e deslanchar em diversos países. As causas parecem estar ligadas à prevalência de informações assimétricas nesse mercado, fazendo com que seleção adversa e risco moral, além do risco sistêmico, desestimulem a oferta por parte das companhias seguradoras. Dessa forma, é comum a presença do Estado nesse mercado, desenvolvendo ações que busquem compensar essas deficiências. No entanto, essa intervenção pode envolver gastos extremamente elevados, além de outras medidas, principalmente de cunho institucional, e exigir prazos muito longos para apresentar resultados favoráveis.

No Brasil, as experiências mais significativas ocorreram por meio do envolvimento direto do governo em programas de seguro agrícola de abrangência nacional, que apresentaram sérios problemas operacionais e administrativos, com histórico de elevadas fraudes e ineficiências. Com a aprovação da Lei $\mathrm{n}^{\mathrm{o}}$ 10.823, o governo brasileiro espera agora ver desenvolvido um modelo de gestão de riscos rurais de responsabilidade inteiramente privada, contando com apoio estatal principalmente na subvenção ao prêmio pago pelos produtores e não mais em resultados operacionais de programas.

\section{Referencial teórico para o seguro agrícola}

A teoria neoclássica da firma inicia-se com a análise da teoria do preço e da produção sob condições de concorrência perfeita, na qual quatro grandes condições são atendidas:

a) há um grande número de pequenas empresas,

b) há homogeneidade nos produtos vendidos,

c) todos os recursos tem mobilidade perfeita, e

d) todos os agentes econômicos dispõem de informação perfeita.

Dessa forma, a firma tem conhecimento exato sobre o mercado consumidor, a disponibilidade e preços dos insumos e, em função da tecnologia disponível, pode planejar sua de produção de forma a 
maximizar seu lucro no ponto no qual o preço de seu produto se iguala ao seu custo marginal de produção.

A teoria econômica postula, assim, que, na ausência de quaisquer distorções, o funcionamento livre e competitivo dos mercados asseguraria a eficiência alocativa dos recursos produtivos da sociedade. No entanto, há ocasiões em que mercados não regulados, deixados a seu livre funcionamento, dão origem a resultados econômicos não eficientes ou indesejados do ponto de vista social. A essa situação denomina-se "falha de mercado" e, em geral, é provocada pela existência de monopólios ou de estruturas de mercado excessivamente concentradas, ausência ou inexpressividade de alguns mercados, informação imperfeita dos agentes econômicos, custos de transação elevados, oferta de bens públicos e existência de externalidades, dentre outros.

A maioria dos livros-texto de microeconomia aborda o tema das falhas de mercado. Entre essas falhas, as que mais interessam, neste trabalho, são as informações assimétricas, a seleção adversa e o risco moral. A existência desses eventos inibe a formação de mercados de seguros, como será demonstrado nas próximas páginas.

\subsection{Informação assimétrica}

Ao analisar a organização e o comportamento dos consumidores, das firmas e dos mercados, em especial os monopólios e a concorrência imperfeita, a teoria econômica admite e incorpora aspectos relevantes acerca da existência de informação assimétrica nos mercados e suas conseqüências sobre o consumidor, a firma e a economia de uma maneira geral. No entanto, foi somente em décadas mais recentes que esta questão passou a ganhar importância crescente nos foros acadêmicos, sendo impulsionada principalmente pelos estudos de George Akerlof ao avaliar as implicações das informações assimétricas sobre a qualidade de um produto.

Um importante e particular referencial para a compreensão dos problemas causados pelas informações assimétricas pode ser encontrado na teoria microeconômica. Assimetria de informação ocorre quando um dos lados de uma transação econômica detém mais informações do que a outra sobre o bem ou serviço sendo transacionado. Nas análises conceituais sobre assimetria da informação abordam-se questões da relação agente-principal, risco moral e seleção adversa. A maioria dos livros-texto, ao analisar essas questões, faz uso do exemplo inicial de 
Akerlof sobre o mercado de carros usados nos EUA e, a partir daí, teorizam-no e generalizam sua aplicação para outros mercados da economia, como seguro, crédito e empregos.

Pindyck e Rubinfeld (2002) destacam que as informações assimétricas são uma característica de muitas situações econômicas e explicam muitos arranjos institucionais que ocorrem na sociedade. Stiglitz e Walsh (2003), ao analisarem o comportamento do mercado de carros usados nos EUA, avaliam a importância da questão da qualidade e de como o mecanismo de preços deve funcionar como sinalizador para as decisões dos consumidores. Dessa forma, afirmam que os consumidores usam esse mecanismo para julgar o que pretendem comprar e fazem inferências sobre a qualidade dos bens a partir do preço cobrado.

No entanto, em mercados com informações imperfeitas, as firmas têm condições de fixar seus preços, levando em consideração o quê os consumidores podem pensar em relação à qualidade do produto à venda. Assim, "(a) preocupação de que os consumidores possam (correta ou incorretamente) fazer inferências sobre a qualidade impede a eficácia da competição de preços." (STIGLITZ e WALSH , 2003, p. 241). Ainda segundo estes autores, sob essas circunstâncias, mesmo quando as firmas não conseguem vender toda a quantidade que desejam ao preço corrente, elas não reduzem os preços, sendo então possível manter uma situação em que ocorre um aparente excesso de oferta de bens. Concluem os autores que "(a) informação imperfeita significa que o equilíbrio é alcançado fora da interseção entre as curvas de oferta e de demanda" (STIGLITZ e WALSH , 2003, p. 241).

\subsection{Seleção adversa}

Pindyck e Rubinfeld (2002, p.604) afirmam que "a seleção adversa surge quando produtos de qualidades distintas são vendidos ao mesmo preço, porque compradores e vendedores não estão suficientemente informados para determinar a qualidade real do produto no momento da compra. Como resultado, muitos produtos de baixa qualidade e poucos de alta são vendidos no mercado." Wenner e Arias (2003, p.2), tratando do problema da presença da seleção adversa no mercado de seguros, apresentam a seguinte definição:

A seleção adversa em mercados de seguro refere-se à situação em que as seguradoras acham impossível ou muito caro distinguir 
entre clientes de alto risco e de baixo risco, então precificam contratos de seguro a um preço médio para todos, o que é inadequado e insustentável. Isto resulta em cobrar, para contratos idênticos, pouco dos clientes de alto risco e muito dos clientes de baixo risco. Com o tempo, os clientes de baixo risco abandonam o mercado e a seguradora fica com um grupo de clientes de alto risco, com expectativa de indenização mais elevada, que afeta negativamente sua rentabilidade. (tradução livre).

Eisenhauer (2004, p.166) faz uso do que, segundo ele, é uma definição típica dos livros-texto:

A seleção adversa decorre da informação assimétrica: clientes de seguro conhecem suas probabilidades de perda, mas companhias de seguro não conseguem distinguir entre clientes de alto risco e de baixo risco. Se as seguradoras cobram uma taxa de prêmio médio de todos os clientes, indivíduos de alto risco receberão um subsídio e comprarão mais cobertura do que os clientes de baixo risco, que acharão os prêmios caros relativamente às suas exposições de risco. Assim, a maioria da cobertura é comprada por indivíduos de alto risco e, conseqüentemente, os pedidos de indenização superarão o nível previsto pelas seguradoras. (tradução livre).

\subsection{Risco moral}

A ineficiência econômica presente em mercados sob informações assimétricas também pode ser facilmente observada na análise do risco moral. Diz-se que há ocorrência de risco moral toda vez que um agente econômico, contratante ou contratado para a realização de um serviço, por não ter seu comportamento devidamente monitorado pela outra parte, altera seu comportamento após a finalização da negociação, aumentando a probabilidade de ocorrência de um dano ou acidente. Assim, a expressão refere-se ao risco de comportamento imoral ou inadequado diante da ausência de monitoramento pela parte considerada vulnerável.

A situação de risco moral encontra-se muito presente na abordagem da relação agente-principal, no qual o agente representa a parte contratada por um principal para atingir determinados objetivos fixados por este último, o qual é afetado pela ação indesejada do agente. Dessa 
forma, um dos objetivos do principal é desenhar adequadamente um contrato, ou um mecanismo de compensação, que estabeleça incentivos para que o agente atue conforme o seu interesse.

Um mercado em que o risco moral se encontra permanentemente presente é o de seguros. A probabilidade que um segurado, que não pode ser adequadamente monitorado, altere seu comportamento pelo fato de haver contratado seguro é sempre muito elevada e constitui uma fonte de permanente preocupação para as seguradoras. Azevedo-Filho (2001, p.3) define a presença do risco moral no mercado de seguros agrícolas da seguinte forma:

O seguro acaba estimulando ações por parte do segurado - não desejadas ou observadas por parte do segurador - que podem aumentar a freqüência e/ou montante das indenizações. Essas ações não ocorreriam se esse produtor não estivesse coberto pelo seguro. (...)

Pindyck e Rubinfeld (2002, p.613) ao abordarem esta questão, assim definem o risco moral no mercado de seguros: "Ocorrência relacionada às ações da parte segurada que não podem ser observadas pela parte seguradora, mas que podem afetar a probabilidade ou a magnitude de um pagamento associado a um sinistro." Skees (1999a) destaca que, enquanto o potencial para a seleção adversa encontra-se em ação antes da compra do seguro, o risco moral manifesta-se após a compra.

\subsection{A resposta da firma ao risco}

É fácil perceber que a presença do risco (moral ou outro qualquer) afeta as decisões de produção e a oferta dos agentes econômicos. Para fins de análise neste texto, ao se considerar o setor agrícola, o produtor rural será sempre tratado como uma firma, uma vez que a racionalidade de suas decisões econômicas em relação à produção equivale a de uma firma, independentemente do tamanho e da forma jurídica como está constituída.

Assim, uma firma agrícola quase nunca sabe com certeza o quanto será produzido e a que preço sua produção será vendida. Isso porque, neste setor, verifica-se com muita freqüência uma elevada instabilidade em relação ao clima, às pragas e aos preços dos produtos agrícolas. Os primeiros costumam ser tratados como risco natural ou tecnológico, por ter sua produtividade variando em função da ação da natureza. Os 
últimos, ao lidarem com preços dos produtos, costumam ser referenciados como risco de mercado.

Em um mercado competitivo, como geralmente se representam os mercados agrícolas, a presença do risco para uma firma avessa a ele faz com que seu nível de produção se apresente menor do que o nível ótimo. Para essa firma, conforme ilustrado na Figura 1, o efeito do risco é o de deslocar sua curva de custo marginal para a esquerda, de $\mathrm{CMg}_{1}$ para $\mathrm{CMg}_{2}$, reduzindo o seu nível de produção de $\mathrm{Q}_{1}$ para $\mathrm{Q}_{2}$.

Figura 1. Resposta da curva de oferta de uma firma avessa ao risco

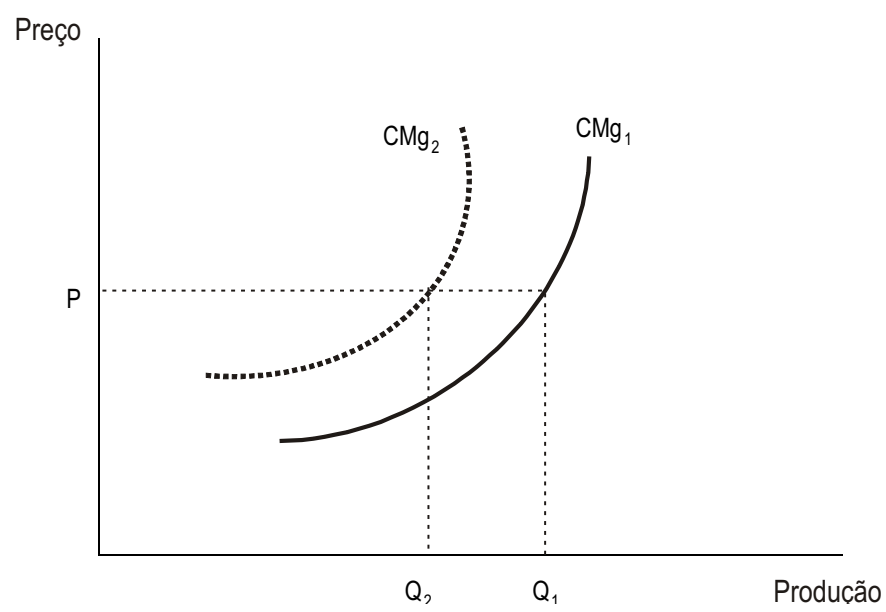

Fonte: AAFC (1998), com adaptações dos autores

Em um mercado operando sob concorrência perfeita, o efeito da disponibilidade de seguro sobre a curva de oferta de um produtor avesso ao risco pode ser observado por meio da Figura 2. Na ausência de seguro, o produtor oferta sobre a curva $O$, a qual, ao preço de mercado $P$, faz com que a quantidade demandada seja $Q$, o que lhe confere uma receita bruta representada pela área $a b c$. A introdução do seguro faz com que a curva de oferta do produtor se desloque para a direita, situando-se agora em Osa, com a quantidade de equilíbrio situando em Qsa. Uma política pública que subsidie os custos do prêmio tem o mesmo efeito de um aumento no preço de venda do produto. Assim, o preço recebido pelo produtor desloca-se para Psas, o qual, ao nível da nova curva de oferta Osa, corresponde a uma nova quantidade ofertada Qsas. A nova receita auferida pelo produtor corresponde agora à área $d f f_{c}$ na Figura 2. 
Figura 2. Efeito da introdução do seguro sobre a curva de oferta

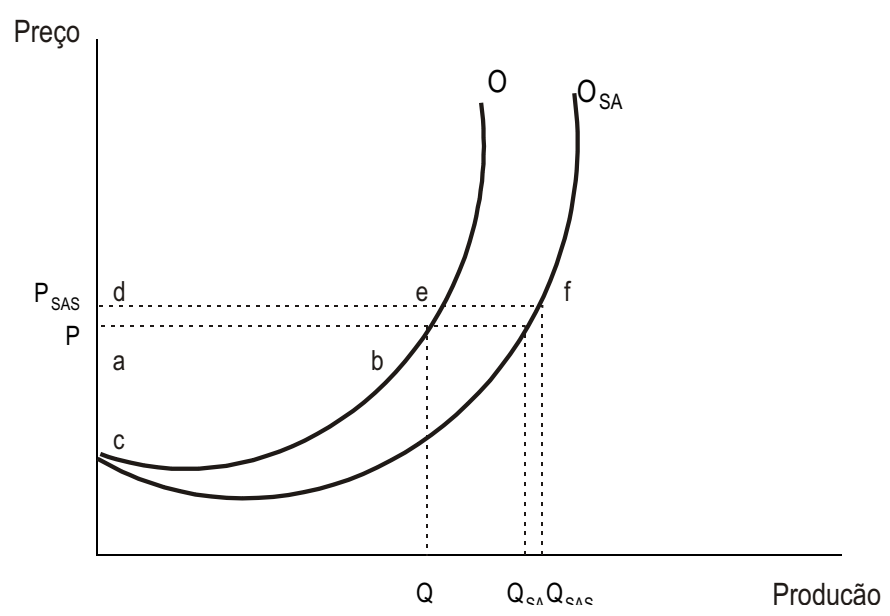

Fonte: AAFC (1998), com adaptações dos autores

\section{O seguro agrícola nos EUA}

\subsection{Contexto histórico}

Os EUA desenvolvem mecanismos formais de gestão de riscos agrícolas desde finais do século XIX. As primeiras experiências com seguros agrícolas privados de riscos múltiplos datam de 1899, tendo prosseguido até o final da década de 1920 . No entanto, todas fracassaram e foram logo abandonadas (BARNETT, 2000 e OZAKI, 2005). Devido ao insucesso dessas iniciativas privadas, o governo dos EUA criou, em 1938, a Federal Crop Insurance Corporation (FCIC), vinculada ao United States Department of Agriculture (USDA), com o objetivo de formular políticas para o desenvolvimento do seguro agrícola, administrar programas e elaborar pesquisas.

Sob a FCIC criou-se, inicialmente, um programa experimental restrito às principais culturas e regiões produtoras. Entretanto, logo nos primeiros anos, o programa apresentou resultados financeiros negativos, a despeito do fato de não ter havido problemas climáticos significativos, sendo necessário aportes do Tesouro norte-americano para cobrir os déficits gerados. Ozaki (2005) afirma que tais resultados foram devidos principalmente a técnicas pouco desenvolvidas de precificação e cálculos 
incorretos de estimativa de produtividade, aliados ainda a problemas de seleção adversa.

Novos produtos e regiões foram paulatinamente incluídos no programa e alguns ajustes e aperfeiçoamentos foram também tentados sem que houvesse, no entanto, uma melhoria substancial dos resultados financeiros. Assim, entre 1939 e 1978, o programa alternou resultados atuariais negativos e favoráveis, com uma leve preponderância para esses últimos. Em 1979, o programa já atendia 29 culturas e beneficiava pelo menos uma cultura nos 1.526 counties $^{3}$ dos 3.100 existentes nos EUA (BARNETT, 2000).

Em 1980, o Crop Insurance Improvement Act determinou que o seguro agrícola seria a principal forma de proteção contra desastres naturais dos produtores agrícolas norte-americanos e expressou a intenção de que as ajudas "ad hoc" fossem extintas. Para tanto, instituiu uma série de medidas, visando ao desenvolvimento do instrumento. Dentre essas medidas, destacaram-se a introdução de subsídios ao prêmio pago pelos produtores e a participação de companhias seguradoras privadas na operacionalização do programa e no compartilhamento parcial dos riscos $^{4}$. As seguradoras também passaram a receber subsídios do governo para custear os gastos operacionais e o desenvolvimento de novos produtos de seguro. O programa também ampliou consideravelmente o rol de produtos agrícolas passíveis de cobertura e as regiões beneficiadas. Com o objetivo de oferecer maior segurança às companhias privadas, o governo introduziu, também, um esquema especial de resseguro intitulado Standard Reinsurance Agreement (SRA), no qual oferece às seguradoras diversas formas de cessão de riscos ${ }^{5}$.

Com o fortalecimento do programa, julgou-se que não haveria mais a necessidade de ajuda de emergência aos produtores rurais em decorrência de problemas climáticos e que a participação da área segurada com as culturas elegíveis ao programa alcançasse cerca de 50\% até o final da década de 80 (GLAUBER, 2004). Entretanto, a seca ocorrida em 1988 e a constatação de que a adesão ao programa alcançava apenas $25 \%$ de todos os produtores fizeram com que o Congresso aprovasse nova

\footnotetext{
${ }^{3}$ County é uma subdivisão político-administrativa do Estado nos EUA, equivalente ao município no Brasil.

${ }^{4}$ Até 1980, as companhias seguradoras apenas comercializavam os produtos de seguro desenvolvidos pela FCIC.

${ }^{5}$ Para mais detalhes, vide item 4.2.
} 
- A experiência norte-americana com o seguro agrícola: lições ao Brasil?

ajuda aos produtores rurais para cobrir as perdas dos produtores (GLAUBER e COLLINS, 2002).

A Tabela 1 mostra alguns indicadores selecionados do programa de seguro agrícola dos EUA entre 1981 e 2003. De 1981 a 1993, o desempenho atuarial do programa foi desastroso. Em nenhum dos anos o índice de sinistralidade foi inferior a 1, tendo a média do período se situado em 1,52. O déficit nominal acumulado do programa (total de indenizações menos o total de prêmios arrecadados) no período foi superior a US $\$ 3,65$ bilhões, significando uma média anual de US\$281 milhões. A média anual da área total segurada no mesmo período foi de apenas 62,5 milhões de $\operatorname{acres}^{6} \mathrm{e}$, segundo Glauber (2004), teria sido ainda menor se a legislação que autorizou a ajuda financeira, devido aos problemas climáticos de 1988 e 1989, não estivesse condicionada à exigência de compra de seguro agrícola básico no ano subseqüente.

Ao final dos anos 80, tornava-se claro que os níveis de subsídios concedidos eram insuficientes para fazer com que a participação do seguro agrícola alcançasse os desejados $50 \%$ do total da área plantada e que, para tanto, fazia-se necessário uma elevação no percentual dos subsídios ou a obrigatoriedade na contratação do seguro agrícola (GLAUBER, 2004). Estudos conduzidos por Gardner e Kramer (1986), Wright e Hewitt (1994) e Goodwin e Smith (1995), citados por Glauber (2004), concluíam que para se atingir um nível de participação de $50 \%$ seria necessária uma taxa de subsídio da ordem de $50 \%$.

Em 1994, o Congresso e o governo federal dos EUA acordaram a edição do Crop Insurance Reform Act. Essa nova legislação determinava mais uma vez o fim dos pagamentos "ad hoc" para ajuda na ocorrência de catástrofes naturais, autorizava o aumento nos percentuais de subsídio aos prêmios do seguro agrícola e tornava obrigatória a contratação do seguro agrícola na modalidade mais básica, preventiva de catástrofes -Catastrophic Risk Protection (CAT) - pelos beneficiários dos principais programas governamentais de apoio aos produtores rurais. O CAT cobria apenas $50 \%$ da produtividade histórica do produtor e era integralmente subsidiado pelo governo.

${ }^{6} \mathrm{O}$ acre é uma medida de superfície e corresponde a 0,4047 hectare. Para fins de comparação, a média da área colhida nos anos de 1982, 1987 e 1992 nos EUA foi de 301,5 milhões de acres (USDA/NASS, 2005 - estatística disponível no sítio www.nass.usda.gov - acesso em 01/08/2006). 
Tabela 1. EUA: Indicadores Selecionados do Programa de Seguro Agrícola ${ }^{1}$

\begin{tabular}{|c|c|c|c|c|c|c|c|c|}
\hline$\stackrel{8}{\xi}$ & 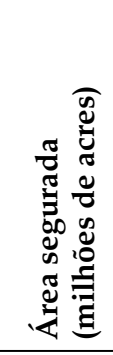 & 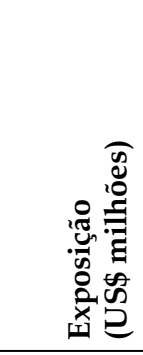 & 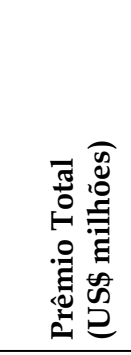 & 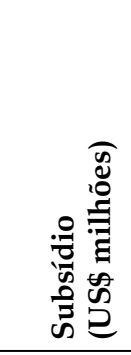 & 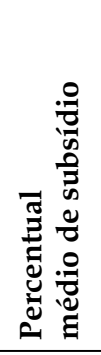 & 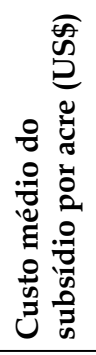 & 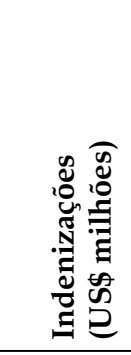 & 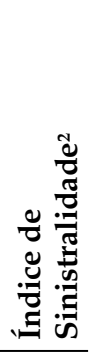 \\
\hline 1981 & 45,00 & 5981,20 & 376,80 & 47,00 & 12,50 & 1,04 & 407,30 & 1,08 \\
\hline 1982 & 42,70 & 6124,90 & 396,10 & 91,30 & 23,00 & 2,14 & 529,10 & 1,34 \\
\hline 1983 & 27,90 & 4369,90 & 285,80 & 63,70 & 22,30 & 2,28 & 583,70 & 2,04 \\
\hline 1984 & 42,70 & 6619,60 & 433,90 & 98,30 & 22,70 & 2,30 & 638,40 & 1,47 \\
\hline 1985 & 48,60 & 7159,90 & 439,80 & 100,10 & 22,80 & 2,06 & 683,10 & 1,55 \\
\hline 1986 & 48,70 & 6230,00 & 379,70 & 88,10 & 23,20 & 1,81 & 615,70 & 1,62 \\
\hline 1987 & 49,10 & 6094,90 & 365,10 & 87,60 & 24,00 & 1,78 & 369,80 & 1,01 \\
\hline 1988 & 55,60 & 6964,70 & 436,40 & 108,00 & 24,70 & 1,94 & 1067,60 & 2,45 \\
\hline 1989 & 101,70 & 13620,70 & 819,40 & 206,30 & 25,20 & 2,03 & 1215,30 & 1,48 \\
\hline 1990 & 101,30 & 12818,20 & 835,50 & 215,10 & 25,70 & 2,12 & 1033,60 & 1,24 \\
\hline 1991 & 82,40 & 11216,00 & 737,00 & 190,50 & 25,80 & 2,31 & 955,30 & 1,30 \\
\hline 1992 & 83,10 & 11334,10 & 758,80 & 196,80 & 25,90 & 2,37 & 918,20 & 1,21 \\
\hline 1993 & 83,70 & 11353,40 & 755,70 & 200,10 & 26,50 & 2,39 & 1655,50 & 2,19 \\
\hline 1994 & 99,60 & 13608,40 & 949,40 & 255,30 & 26,90 & 2,56 & 601,10 & 0,63 \\
\hline 1995 & 220,50 & 23728,50 & 1543,30 & 889,50 & 57,60 & 4,03 & 1567,70 & 1,02 \\
\hline 1996 & 204,90 & 26876,80 & 1838,60 & 982,10 & 53,40 & 4,79 & 1492,70 & 0,81 \\
\hline 1997 & 182,20 & 25459,00 & 1775,40 & 903,10 & 50,90 & 4,96 & 993,60 & 0,56 \\
\hline 1998 & 181,80 & 27921,40 & 1875,90 & 947,60 & 50,50 & 5,21 & 1677,50 & 0,89 \\
\hline 1999 & 196,90 & 30939,50 & 2310,10 & 1394,00 & 60,30 & 7,08 & 2434,70 & 1,05 \\
\hline 2000 & 206,50 & 34443,80 & 2540,20 & 1365,80 & 53,80 & 6,61 & 2594,80 & 1,02 \\
\hline 2001 & 211,30 & 36732,80 & 2961,90 & 1771,80 & 59,80 & 8,39 & 2959,80 & 1,00 \\
\hline 2002 & 214,90 & 37311,30 & 2915,90 & 1741,50 & 59,70 & 8,10 & 4066,10 & 1,39 \\
\hline 2003 & 217,40 & 40643,60 & 3430,60 & 2041,70 & 59,50 & 9,39 & 3226,50 & 0,94 \\
\hline $1981-93$ & 62,50 & 8452,90 & 540,00 & 130,20 & 24,10 & 2,08 & 821,00 & 1,52 \\
\hline 1994-03 & 193,60 & 29766,50 & 2214,10 & 1229,20 & 55,50 & 6,35 & 2161,50 & 0,98 \\
\hline
\end{tabular}

Obs.: (1) os valores são expressos em termos nominais; (2) indenização dividida pelo prêmio total. Fonte: USDA-RMA. Extraído de Glauber (2004), com modificações pelos autores. 
As medidas adotadas surtiram efeito imediato, fazendo com que a área coberta por seguro agrícola em 1995 fosse a maior da história do programa, com mais de $80 \%$ de participação sobre a área elegível ao programa, tendo a modalidade CAT sido contratada em mais da metade da área segurada. Apesar desses resultados, as críticas dos produtores norte-americanos à obrigatoriedade e pressão por produtos de seguro mais sofisticados fizeram com que o Congresso eliminasse a compulsoriedade de cobertura pelo CAT, reduzindo substancialmente sua contratação nos anos subseqüentes.

O Federal Agriculture Improvement and Reform Act (Fair Act) de 1996 procurou desenvolver novas e melhores formas de gestão de riscos a serem oferecidas aos produtores rurais e instituiu a Risk Management Agency - RMA (Agência de Gestão de Riscos), com o objetivo de supervisionar e administrar as atividades diárias sob responsabilidade da FCIC. No rol de produtos de seguro de cobertura a riscos múltiplos, foram criadas também novas modalidades, com destaque para os chamados "seguros de receita7", no qual não mais se segurava apenas a produtividade e, sim, a receita financeira a ser gerada pela atividade agrícola do segurado.

O aumento nos percentuais de subsídios e a introdução das novas modalidades de seguro de receita contribuíram para que nos anos seguintes os níveis de área segurada se situassem próximos aos verificados em 1994 e 1995. A Figura 3 exibe a evolução da área segurada no período 1981-2003 e a Figura 4 apresenta a evolução dos percentuais médios de subsídio ao prêmio no mesmo período. Destaca-se, porém, que agora além de não haver mais a obrigatoriedade, percebia-se uma alteração na composição das modalidades escolhidas pelos produtores rurais, os quais migravam dos seguros básicos de produtividade para os novos produtos de seguro de receita que tiveram forte aceitação. Também contribuiu para esse resultado a introdução de descontos ao prêmio dos seguros do tipo buy-up ${ }^{8}$, instituídos a partir de 1999, que representavam um subsídio adicional.

\footnotetext{
${ }^{7}$ Os seguros de receita são também freqüentemente denominados como seguros de renda.

${ }^{8}$ O termo buy-up refere-se a seguros com níveis de cobertura superiores ao seguro básico de catástrofes (CAT).
} 
Figura 3. EUA: evolução da área segurada - 1981 a 2003

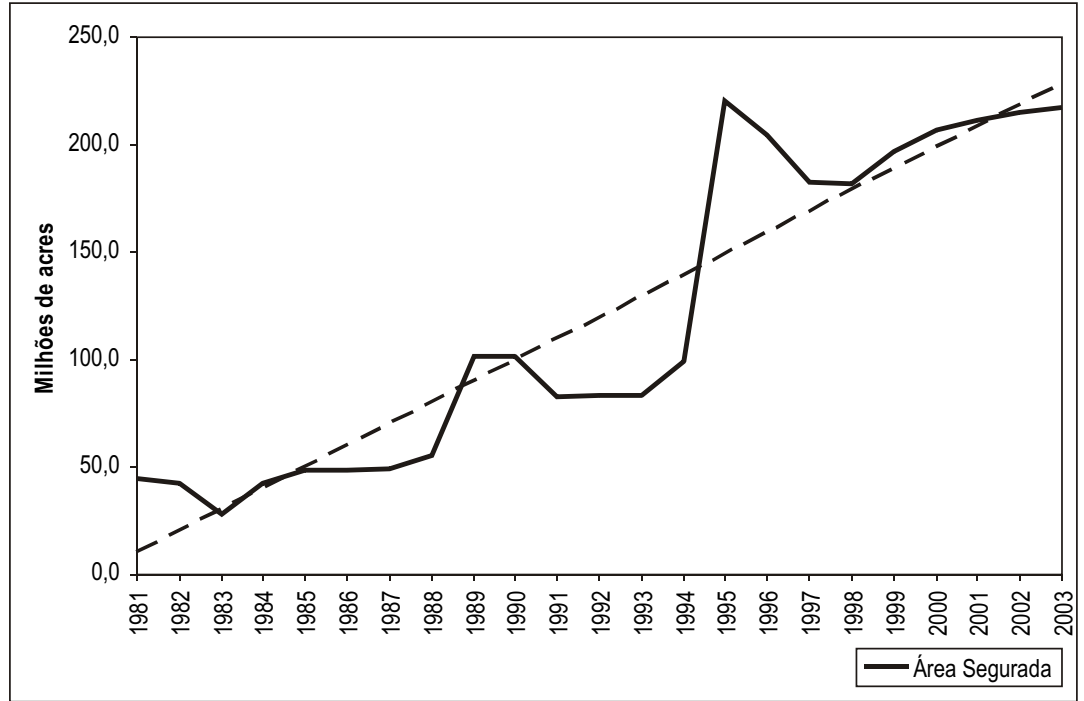

Fonte: USDA-RMA, extraído de GLAUBER (2004).

Figura 4. EUA: percentuais médios de subsídio ao prêmio - 1981 a 2003

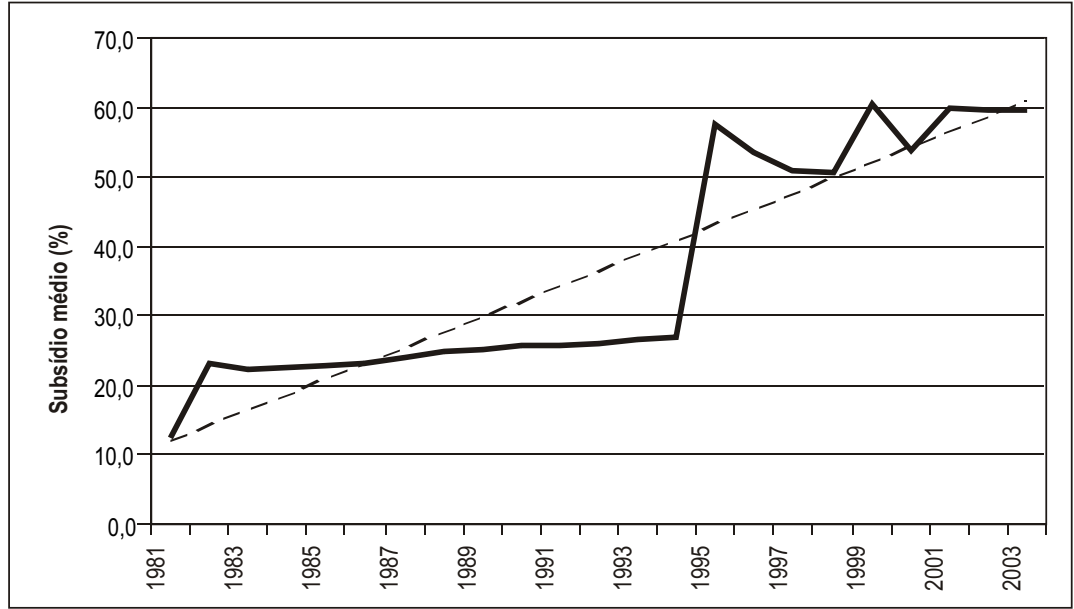

Fonte: USDA-RMA, extraído de GLAUBER (2004).

Elaboração: os autores

Em 2000, foi assinado o Agricultural Risk Protection Act (ARPA) que tornou a elevar os subsídios ao prêmio e reduziu as diferenças existentes entre os diversos níveis de subsídios em função dos níveis de cobertura, assim como 
equalizou as taxas de subsídio entre os seguros de produtividade e os seguros de receita. Com base em dados preliminares da contratação de seguro para a safra de trigo de 2001, Young et al. (2001) afirmavam que a ARPA contribuía positivamente para o aumento da área segurada, a transferência de seguros de produtividade para seguros de receita e para a escolha de níveis mais altos de cobertura pelos produtores rurais.

Em 2003, o programa segurou um total de 217,4 milhões de acres, com uma exposição acima de US $\$ 40,6$ bilhões, um total de prêmios de mais de US $\$ 3,4$ bilhões e subsídios superando US\$ 2 bilhões, equivalentes a um percentual médio de 59,5\% (Tabela 1). Para aquele mesmo ano, o índice de sinistralidade foi de 0,94. A Figura 5, que exibe o índice de sinistralidade observado ao longo do período 1981-2003, permite observar que entre 1981 e 1993 a sinistralidade do programa manteve-se sempre acima de 1 e o índice médio do período foi de 1,52. Entre 1994 e 2003, no entanto, a sinistralidade superou $1 \mathrm{em}$ apenas quatro anos e o índice médio foi de 0,98 , demonstrando um adequado equilíbrio atuarial.

Para 2004, as estimativas indicavam um total de 215 milhões de acres segurados, significando uma participação de $80 \%$ em relação à área plantada elegível ao programa e uma exposição superior a US $\$ 46$ bilhões (Davidson, 2004, citado por GLAUBER, 2004). Atualmente, o programa compreende 22 planos de seguros, contemplando mais de 100 culturas e com atuação em todo os EUA.

Figura 5. EUA: índice de sinistralidade - 1981 a 2003

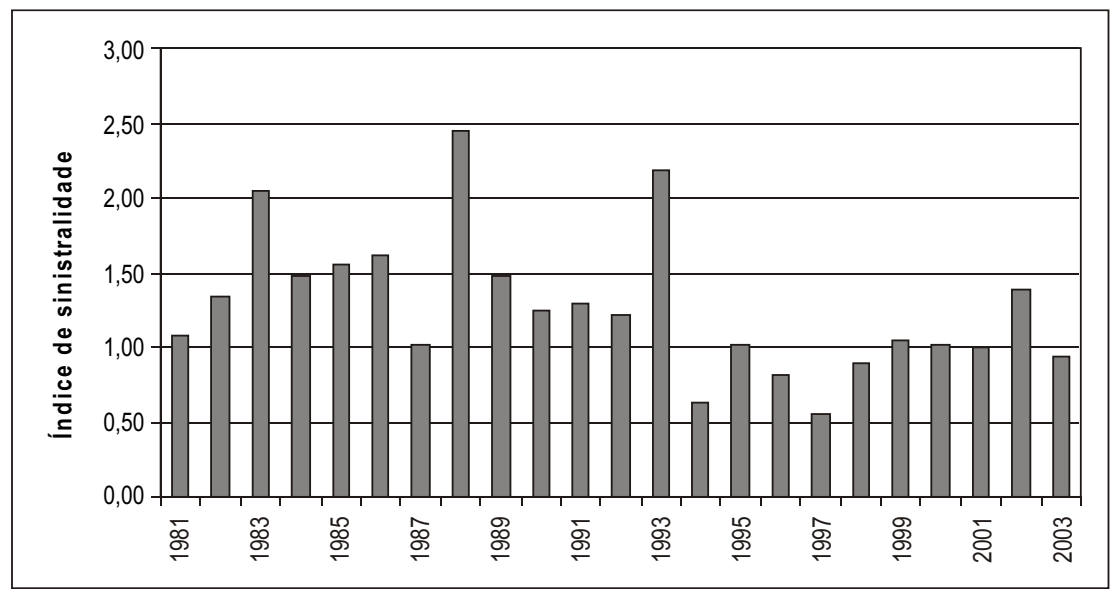

Fonte: USDA-RMA, extraído de GLAUBER (2004).

Elaboração: os autores 


\subsection{Resseguro}

A peça-chave do modelo de resseguro estabelecido no programa de seguro agrícola dos EUA é o Standard Reinsurance Agreement (SRA), renegociado periodicamente ${ }^{9}$. Nele são definidas todas as cláusulas que regem o relacionamento entre as seguradoras privadas e a FCIC no tocante à participação das primeiras no programa. Dessa forma, desde o subsídio às estimativas de despesas administrativas e operacionais até a política de retenção, cessão e compartilhamento de riscos, lucros e perdas estão ali incluídos.

Uma das características mais fortes do SRA refere-se à exigência às seguradoras participantes do programa de que a nenhum produtor rural elegível ao programa pode ser negado o direito ao seguro agrícola em qualquer um dos cinqüenta estados da federação por uma seguradora que lá atue ${ }^{10}$. Assim, uma seguradora operando em um estado não pode discriminar entre produtores, culturas ou produtos de seguro naquele estado. Tal determinação se encontra claramente expressa na Seção II A.2 do Standard Reinsurance Agreement (SRA) de 200511.

Pelo SRA, as seguradoras não podem ceder ou reter o total do risco subscrito em uma apólice. Pode haver uma cessão proporcional do prêmio e da responsabilidade (exposição) à FCIC, bem como uma cessão não proporcional do prêmio e da responsabilidade. O risco cedido por uma seguradora privada à FCIC é de inteira responsabilidade desta última. Para o restante de risco mantido pela seguradora, ela pode recorrer ao mercado privado de resseguro.

No relacionamento com a FCIC, uma seguradora deve escolher entre três fundos para direcionar suas apólices, em cada um dos estados em que ela opera: o Assigned Risk Fund, o Developmental Fund e o Commercial

\footnotetext{
${ }^{9} \mathrm{O}$ atual SRA entrou em efetividade em 2005 e pode ser encontrado no sítio da RMA: http://www.rma.usda.gov. O acordo anterior era de 1998.

${ }^{10}$ Segundo Dismukes (2002, p.9), a exigência se aplica somente aos planos de seguro desenvolvidos pela FCIC/RMA. Segundo o autor, uma seguradora não é obrigada a oferecer planos de seguro desenvolvidos de forma privada, porém, elegíveis a subsídios e resseguro pela FCIC. No entanto, caso ela se decida por ofertar produtos de seguro ela é obrigado a fazê-lo em todos os estados aprovados.

11 “... the Company must offer and market all plans of insurance for all crops in any State where actuarial documents are available in which it writes an eligible crop insurance contract and must accept and approve all applications from all eligible producers.". Ker (2001, p.559) também cita essa mesma exigência no SRA de 1998.
} 
- A experiência norte-americana com o seguro agrícola: lições ao Brasil?

Fund ${ }^{12}$. Cada um desses fundos apresenta um nível próprio de exigência em termos de cessão e retenção de riscos e políticas de compartilhamento de perdas e lucros de subscrição, os quais variam entre os estados, conforme os riscos que apresentem.

Ao Assigned Risk Fund (ARF) são direcionadas às apólices consideradas de maior risco. A percentagem máxima de risco em cada estado que pode ser direcionado a este fundo é estipulada no Acordo. Esse percentual varia de $10 \%$ a $75 \%{ }^{13}$. Ao Developmental Fund (DF), as companhias de seguro direcionam as apólices de risco intermediário que encontram dificuldade de serem resseguradas em bases totalmente comerciais. A seguradora deve reter, no mínimo, 35\% do prêmio da apólice e da exposição a ela associada. Ao Commercial Fund (CF), as seguradoras direcionam os melhores riscos, ou seja, as apólices com menor probabilidade de perda. A seguradora deve reter pelo menos $50 \%$ do prêmio e do risco associado às apólices destinadas a este fundo. Neste fundo e no DF há, ainda, a possibilidade de aplicação do resseguro em bases não proporcionais para a parcela do risco retido pelas seguradoras.

O direcionamento de apólices para diferentes fundos forma a parte proporcional das regras do acordo de resseguro. As regras na parte não proporcional definem a responsabilidade da seguradora pelas perdas. Dependendo do fundo em questão e do montante das perdas, o Acordo determina o tamanho da responsabilidade da seguradora, de forma a que ela seja mais alta para apólices destinadas ao Commercial Fund e menor para apólices depositadas no Assigned Risk Fund. O SRA também define as regras para a divisão de lucros entre a seguradora e a FCIC. Similarmente ao compartilhamento das perdas, a distribuição dos lucros com as apólices também depende do fundo em questão e do montante do ganho com a emissão, de modo a que a parcela da seguradora nos ganhos seja maior no Commercial Fund e menor no Assigned Risk Fund. Em outras palavras, onde a FCIC assume os maiores riscos a parcela do lucro da operação que é destinada às seguradoras é menor e vice-versa.

\footnotetext{
${ }^{12}$ Dentro do Assigned Risk Fund e do Developmental Fund há ainda uma subdivisão entre três fundos em cada um deles.

${ }^{13}$ Para obter os percentuais máximos de risco que podem ser direcionados ao Assigned Risk Fund vide Ker (2001, p.563).
} 


\section{Avaliação dos resultados do programa norte-americano}

Decorridos mais de vinte e cinco anos de sua reestruturação, com a introdução dos subsídios e a participação de companhias seguradoras privadas, pode-se afirmar que o programa de seguro agrícola norte-americano encontra-se consolidado no rol das principais políticas de apoio aos produtores rurais. No entanto, os resultados alcançados ainda deixam a desejar, dando motivos a muitas críticas, principalmente na comunidade científica norte-americana.

Inicialmente, percebe-se que o programa se tornou um importante instrumento para transferência de renda ao setor rural. Goodwin (2001, p. 643) destaca que entre 1981 e 1999 para cada dólar pago por participante do programa uma média de US\$ 1,88 foi recebido em indenização, descaracterizando-o como um programa de seguro se fosse operado em bases privadas. Skees (1999b, p.7) também questiona os objetivos do programa. Para o autor, mais do que um instrumento de apoio à gestão de riscos, ele pode ter se transformado em um mecanismo de mercado para a concessão de mais subsídios aos produtores rurais.

As críticas mais freqüentes, no entanto, referem-se ao fato de o programa ainda beneficiar um número pequeno de produtores rurais e de haver uma grande variação na área segurada e na disponibilidade de produtos de seguro entre as culturas e áreas geográficas beneficiadas (MAKKI e SOMWARU, 2001 e GOODWIN 2001).

No que diz respeito ao desempenho atuarial do programa, apesar da melhoria geral dos índices de sinistralidade, eles escondem uma variância muito grande em relação a culturas e regiões. Young et al. (2001) afirmam que a experiência com soja e milho no meio-oeste tende a apresentar um melhor desempenho atuarial, ao passo que, dentre as principais lavouras, o algodão nas planícies do sul costuma apresentar os piores resultados. Skees (1999b), embora reconheça que o desempenho atuarial do programa em nível nacional tem sido satisfatório, afirma que o índice de sinistralidade agregado mascara problemas que existem em muitas regiões, notadamente no Sul e no Sudeste, particularmente no Texas. Segundo o autor, graves problemas e ineqüidades ocorrem devido a abusos e fraudes no programa. Goodwin (2001) também aponta grande variância nas sinistralidades entre estados, destacando extremos como Iowa, cujo índice de sinistralidade acumulada entre 1980 e 1998 foi de 
1,01, e de Arkansas e Texas, cujos índices no mesmo período foram, respectivamente, de 2,97 e de 2,72.

Skees (1999a) critica fortemente o uso de vultosos subsídios no programa, alertando para o fato de que eles trazem consigo uma grande dose de ineficiência. Para o autor, a sociedade acaba pagando para o produtor rural assumir um risco adicional que ele normalmente não assumiria. Segundo Skees (1999a, p.36) “(o) efeito do subsídio é realocar fatores de produção de uma parte da economia para outra (induzir mais terra, capital e trabalho a serem despendidos na atividade agrícola do que ocorreria sob as simples forças do mercado)..."(tradução livre). No entanto, ainda segundo o autor, é o proprietário dos ativos, principalmente da terra, o maior beneficiário, devido à valorização destes. Este fato se torna ainda mais grave quando se sabe que em cerca de metade das unidades de produção agrícola dos EUA quem efetivamente trabalha a terra não é o proprietário (SKEES, 1999a). Para o autor, tentativas de se forçar uma redução artificial no custo do risco levam pessoas a assumirem novos e diferentes riscos até que seu nível de risco retorne ao ponto em que se encontrava antes da intervenção da política pública, tornando inócua a ação. Produtores continuam a apresentar os mesmos riscos de antes e o subsídio é incorporado ao valor dos ativos, criando barreiras à entrada de novos produtores.

Um dos pontos mais comentados em relação ao programa refere-se à questão de se e como os subsídios alteram a decisão de produção dos agricultores. De uma maneira geral, a maioria dos autores que aborda essa questão reconhece que há efeitos sobre a produção e que esses efeitos, embora pequenos, dependem ainda da influência de outras variáveis. Para Young et al. (2001), a disponibilidade do seguro agrícola subsidiado afeta as decisões do produtor ao criar um incentivo direto à expansão da produção. Usando um modelo de simulação ${ }^{14}$, os resultados mostram um crescimento anual médio de 960.000 acres $(0,4 \%)$ na área plantada com as oito principais culturas nos EUA ao longo do período 2001-2010. Embora todas as culturas apresentem crescimento de área plantada, trigo e algodão respondem por cerca de setenta e cinco por cento desse aumento. Os autores afirmam que, embora modesto em nível nacional, esse resultado mascara importantes impactos regionais e individuais em termos de culturas específicas. Há ainda efeitos sobre os preços, que serão comentados mais adiante.

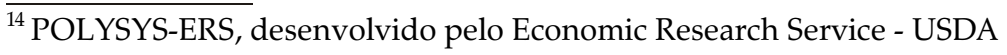


Goodwin et al. (2004) realizaram um estudo junto a produtores de soja e milho do meio-oeste norte-americano e com produtores de trigo e cevada das planícies do norte dos EUA, no período de 1985 a 1993. Os resultados indicaram que uma redução de $30 \%$ nos custos do prêmio do seguro aumentava a participação dos produtores de milho em cerca de $25 \%$ e, de soja, em pouco mais de $20 \%$. No entanto, os impactos sobre a área plantada eram quase nulos: $0,28 \%$ para o milho e um valor estatisticamente insignificante para a soja. No caso do trigo e da cevada os resultados foram similares, com um aumento da participação do primeiro em $20,6 \%$ e do segundo em $19,2 \%$, porém, com um aumento de área plantada desprezível para o primeiro e de $1 \%$ para o segundo, demonstrando assim sua baixa elasticidade.

Skees (1999a) também afirma que o programa influencia as decisões dos produtores. No entanto, apresenta estimativas um pouco mais elevadas de impacto sobre a área plantada. $\mathrm{O}$ autor faz uma análise comparativa do uso da terra do fim dos anos setenta ao final dos anos oitenta para as seis principais culturas dos EUA, com o objetivo de avaliar as mudanças na produção. Ele conclui que a produção deslocou-se do sul e do leste do meio-oeste em direção aos estados de topografia plana. $\mathrm{O}$ autor afirma que esses são estados com maior transferência de risco e, embora reconhecendo que existem outras variáveis que contribuam para justificar o fenômeno, acredita que as transferências de risco expliquem uma parte das mudanças no uso da terra. Segundo o autor, os modelos utilizados sugerem que, para cada $10 \%$ de aumento na transferência de risco, haja um aumento correspondente de 5\% na área plantada. Com base nas expectativas de transferências de subsídios para trigo, algodão e sorgo em 1999, o autor fez uma estimativa de aumento entre $2 \%$ e 3\% da área plantada com essas culturas apenas devido aos subsídios. A estimativa sobre a área plantada com milho e soja foi de $1 \%$ a $2 \%$ maior do que seriam sem os subsídios.

Esse não é, contudo, o único impacto dos subsídios sobre a produção agrícola. Um outro aspecto importante a se considerar diz respeito aos efeitos que a maior produção exerce sobre os preços. Ao resultar em uma maior área plantada e uma oferta de produtos agrícolas superior àquela que seria obtida sem os subsídios, pode-se esperar efeitos de queda de preço. Skees (1999b) estima que os preços sofram uma redução de cerca de $3 \%$, sem precisar a que culturas se refere, enquanto que Young et al. (2001) estimam o mesmo percentual, porém, indicam que se trata de algodão e 
de arroz. Estes mesmos autores estimam, ainda, que no caso do trigo a resposta da produção em relação ao estímulo causado pelo programa como um todo é suficiente para reduzir o preço em cerca de US\$ 0,09 por bushel ${ }^{15}$. Segundo os autores, essa situação prejudica produtores que não contratam seguro agrícola e que terminam por receber preços mais baixos por seus produtos. Young et al. (2001) afirmam ainda que, em função desses ajustamentos de mercado e de algumas despesas administrativas incorridas pelos participantes do programa, os benefícios líquidos aos produtores participantes sofrem uma redução considerável.

Ainda em relação a elasticidades, Goodwin (1993) afirma que à medida que o risco aumenta, a elasticidade-preço da demanda por seguro agrícola cai significativamente. Assim, produtores com baixo risco apresentam uma resposta mais elástica a variações no preço do prêmio do que produtores de maior risco. Os segurados selecionados de forma mais adversa são os que apresentam menor elasticidade ao aumento de preço dos prêmios. Analisando 99 municípios, o trabalho afirma que aqueles que apresentam históricos de maior sinistralidade relativa apresentam menor elasticidade-preço na demanda por seguro agrícola. $\mathrm{O}$ resultado sugere que aumentos muito elevados no valor do prêmio incrementam a sinistralidade das seguradoras na medida em que produtores de menor risco desistem do seguro mais rapidamente e em maior número do que os de maior risco, confirmando assim a presença de seleção adversa. Em uma simulação, o autor calcula que aumentos gerais no preço dos prêmios produzem uma elevação da receita em decorrência da inelasticidade-preço da demanda. No entanto, verifica que a sinistralidade também aumenta e numa proporção superior às receitas, $\mathrm{o}$ que, segundo o autor, sugere que problemas de seleção adversa podem ser agravados por aumentos gerais de prêmios.

Um outro ponto freqüentemente abordado pela literatura especializada diz respeito à influência maléfica das ajudas "ad hoc" proporcionadas pelo Congresso dos EUA aos produtores rurais e o conseqüente desestímulo à contratação de seguro agrícola. Apesar das legislações de 1980 e de 1994, em que se expressava claramente a intenção de não mais fornecer ajuda a desastres naturais, desde o início do programa o Congresso dos EUA já aprovou cerca de US\$ 19 bilhões aos produtores norte-americanos sob a forma de assistência a desastres

${ }^{15} \mathrm{O}$ bushel é uma medida de volume que corresponde a $25,401 \mathrm{~kg}$ para o milho e a 27,216 $\mathrm{kg}$ para a soja. 
(GLAUBER, 2004). Para Skees (1999b, p.37), “uma razão pela qual muitos produtores não compram seguro agrícola é que eles acreditam que quando as coisas derem mal, o governo providenciará seguro grátis na forma de pagamentos de desastres" (tradução livre). Para o autor, ao quebrar continuamente seu compromisso de não mais custear ajudas "ad hoc" o Congresso tem minado o incentivo aos produtores de adquirirem seguro agrícola.

Nessa mesma linha de raciocínio, Skees (1999a) argumenta que as políticas de suporte de preços e garantia de renda adotadas pelos EUA por várias décadas influenciaram para que os mercados futuros não fossem tão utilizados por produtores rurais e alerta que muitos dos novos seguros de receita podem atuar no mesmo sentido, desestimulando ainda mais o uso dos instrumentos de mercado. Nesse sentido, o autor ressalta que o desenvolvimento de seguros de receita deve ser estimulado quando houver efetiva presença de riscos de alta volatilidade de preços paralelamente à presença de elevados riscos naturais que afetem a produtividade. Para o caso de haver preponderância de riscos elevados de variações significativas de preços, então o mais indicado é o uso de mercados futuros. Analogamente, se há preponderância de riscos que afetam a produtividade e não se verifica grande oscilação de preços, o mais indicado é o estímulo ao desenvolvimento de produtos de seguro voltados à cobertura da produtividade da lavoura (SKEES, 1999b, p.7).

Um dos argumentos utilizados na defesa de subsídios como política a ser adotada com vistas ao desenvolvimento do seguro agrícola diz respeito à suposição de que sua contratação por produtores rurais induziria ao uso de maior tecnologia, o quê, por sua vez, provavelmente resultaria em níveis mais elevados de produtividade (SOUSA, 1990a,b). No entanto, esta é uma questão controversa no que tange à experiência norte-americana. Embora se desconheçam estudos científicos com o objetivo específico de avaliar os efeitos do uso do seguro agrícola sobre a produtividade, diversos trabalhos procuraram analisar os efeitos do seguro agrícola sobre o uso de insumos químicos ${ }^{16}$, muitas vezes apresentando resultados conflitantes. Um dos trabalhos de grande repercussão acadêmica e ainda hoje muito referenciado foi conduzido por Horowitz e Lichtenberg (1993). Nele, os autores analisaram produtores de milho do meio-oeste americano e concluíram que a

\footnotetext{
${ }^{16}$ Mishra et al. (2005); Goodwin, Vandeever e Deal (2004); Babcock, Henessy (1996); Horowitz, Lichtenberg (1993).
} 
aquisição de seguro agrícola era positivamente correlacionada com a utilização de insumos químicos. Entretanto, outros estudos citados por Glauber (2004) ${ }^{17}$ atestam que o uso de insumos tende a declinar com a aquisição de seguro agrícola. Sobre esses estudos, o autor afirma que "(a) maioria conclui que os efeitos do seguro agrícola sobre o uso de insumos são negativos, sugerindo que o efeito resultante sobre a produtividade é provavelmente negativo." (tradução livre) (GLAUBER, 2004, p. 1190). Mishra et al. (2005), em um trabalho empírico com trigo de inverno em nível de propriedade rural, concluem que entre produtores daquele cereal de inverno, aqueles que adquirem seguro agrícola de receita tendem a gastar menos com fertilizantes, mas não alteram significativamente os gastos com defensivos.

No que diz respeito à avaliação dos custos do programa, a Figura 6 apresenta a evolução do custo médio do subsídio por acre de terra segurado, a preços reais de $2005^{18}$. Em 1981, os percentuais médios de subsídio ao prêmio se situavam em $12,5 \%$ e o custo médio por acre segurado situava-se um pouco acima de US\$2,00. Entre 1982 e 1994, os percentuais médios de subsídio variaram entre $22,3 \%$ e $26,9 \%$, enquanto que o subsídio por acre segurado variou entre cerca de US\$4,50 e US\$ 3,20. Com a assinatura da Crop Insurance Reform Act, de 1994 e da Agricultural Risk Protection Act, de 2000, os subsídios ao prêmio se elevaram consideravelmente, variando entre cerca de $50 \%$ e $60 \%$, entre 1995 e 2003. Neste mesmo período, o custo médio do subsídio por acre segurado se elevou substancialmente, chegando a atingir aproximadamente US\$10,00, em 2003.

Ainda em relação aos custos do Programa, Glauber (2004, p.1182), utilizando valores reais corrigidos para 2000 e fazendo uso da abordagem marginalista da teoria econômica, demonstra que, com um adequado volume de subsídios, produtores adquirem seguro agrícola. Ele chama a atenção, no entanto, que os custos marginais para essa aquisição são elevados e crescentes. Segundo o autor, como a demanda por seguro agrícola é geralmente inelástica em relação ao prêmio, o custo marginal por unidade de terra da adesão de áreas adicionais ao programa é muito alto. Segundo seus cálculos, o custo marginal do subsídio no período 1981-1994 foi de US\$3,31 por acre, comparado a um subsídio médio por

\footnotetext{
${ }^{17}$ Quiggin, Karagiannis e Stanton (1993); Babcock e Henessy (1996); Smith e Goodwin (1996); Goodwin, Vandeever e Deal (2004).

${ }^{18}$ Deflacionados pela média anual do "Consumer Price Index" norte-americano.
} 
acre de US\$2,73. De 1995 a 1998, o custo marginal do subsídio por acre foi de US\$10,51 contra um subsídio médio por acre de US\$4,99. Já de 1999 a 2003 , o custo marginal por acre foi de US $\$ 25,99$ comparado a um subsídio médio por acre de US\$ 7,76 (Figura 7). Ainda segundo Glauber, esses custos incluem apenas os gastos com o subsídio ao prêmio. Caso fossem computados todos os gastos operacionais, os custos marginais do subsídio por acre se elevariam a cerca de US\$30,00 por acre. Essa interessante análise de Glauber mostra de forma inequívoca a inelasticidade-preço do seguro agrícola, em que para se alcançar taxas elevadas de adesão ao Programa, faz-se necessário a concessão de subsídios em percentuais cada vez mais altos.

Figura 6. EUA: custos médios do subsídio por acre segurado - 1981 a 2003

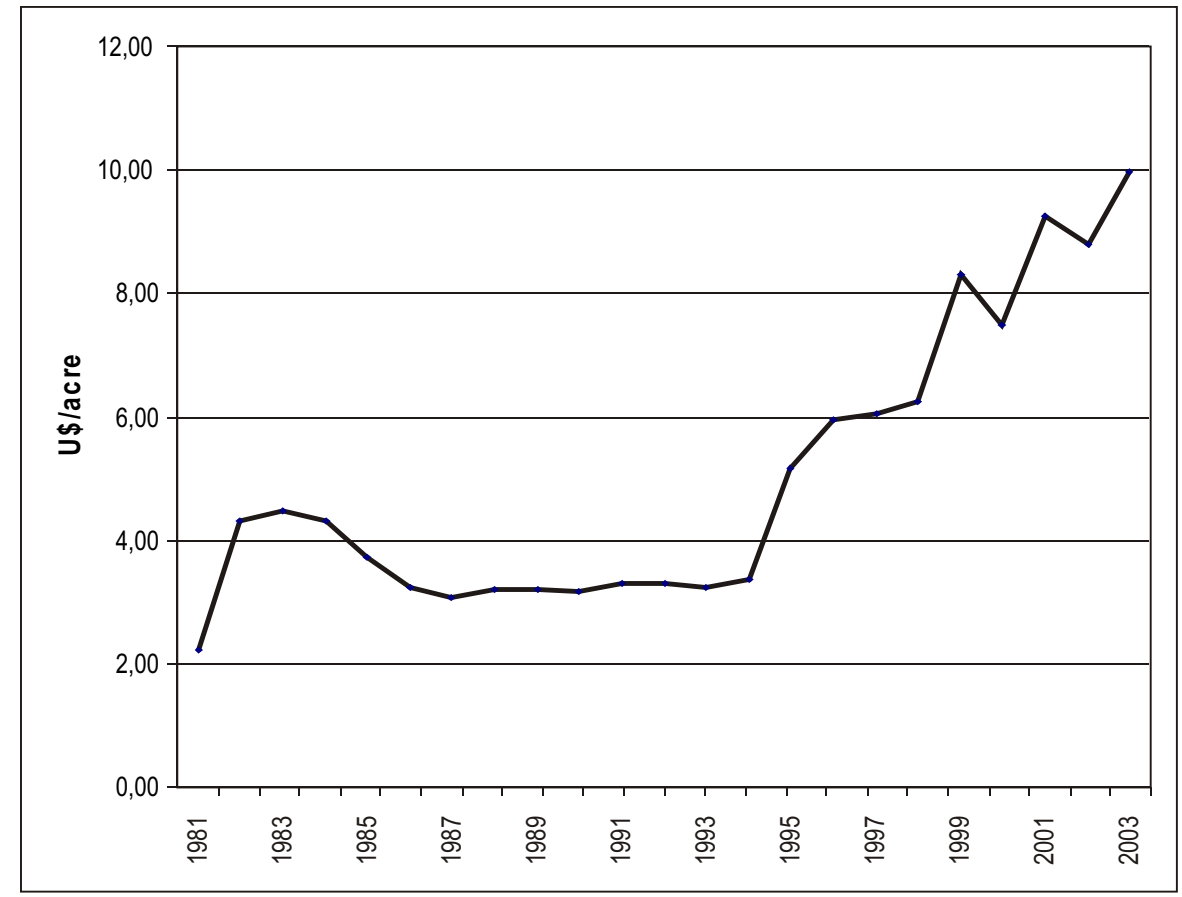

Fonte: USDA-RMA, extraído de GLAUBER (2004).

Elaboração: os autores

Obs.: valores reais de 2005, deflacionados pela média anual do Índice de Preços ao Consumidor (CPI) norte-americano. 
Figura 7. EUA: Custos marginais do subsídio ao prêmio das coberturas Buy-up

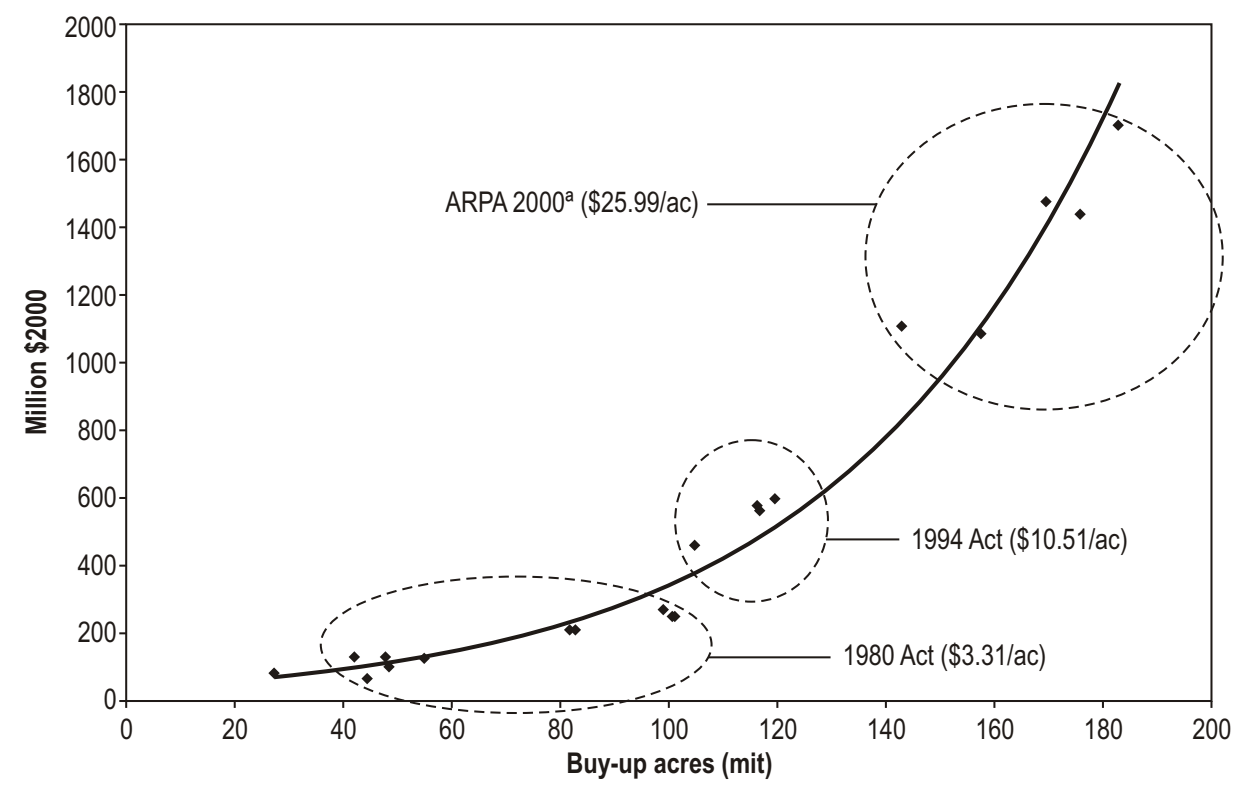

Fonte: USDA, extraído de GLAUBER (2004)

Obs.: valores reais de 2002

Merece comentário, também, o fato de os benefícios do programa de seguro agrícola norte-americano não serem distribuídos de maneira eqüitativa. Da forma como o programa se encontra estruturado, produtores rurais que apresentam riscos mais altos se beneficiam com uma maior transferência de renda. Isso porque os subsídios são fixados como uma percentagem sobre o prêmio. Na medida em que o prêmio reflete a expectativa de risco apresentada por um determinado segurado, um agricultor de maior risco, e conseqüentemente maior prêmio, receberá um montante de subsídio superior a um outro produtor que apresente uma propriedade de mesmo tamanho e explorando a mesma cultura, porém com um risco mais baixo. Analogamente, as áreas e regiões que apresentam riscos mais elevados também acabam recebendo uma maior transferência de renda. Como já mencionado acima, Skees (1999a) chama a atenção para essa questão, demonstrando como a atual estrutura do programa de subsídio ao prêmio do seguro agrícola contribuiu para aumentar a transferência da produção agrícola para regiões de maior risco nos EUA. 
Com referência à iniqüidade do programa, entende-se que uma forma de corrigir as distorções mencionadas seria estabelecer percentuais de subsídios diferenciados em função da experiência histórica e do perfil de risco do segurado. Para tanto, poder-se-ia utilizar os registros históricos do beneficiário, atribuindo-se faixas de subsídios de acordo com os resultados do segurado. Dessa forma, seria estabelecida uma relação inversa entre os percentuais de subsídios concedidos e a experiência verificada com a ocorrência de sinistros e/ou indenizações pagas ao segurado.

Outro aspecto bastante criticado na literatura especializada diz respeito ao uso combinado de diversos programas de apoio ao produtor e de como eles acabam competindo entre si, reduzindo a eficiência de alguns deles. No caso do seguro agrícola, Gray et al. (2004) abordam essa questão em um estudo utilizando o CRC (Crop Revenue Coverage) e concluem que a eficiência desse programa seria muito maior na ausência dos demais pagamentos realizados pelo governo ${ }^{19}$. Os autores sugerem que uma possível razão para os elevados montantes despendidos com o programa de seguro agrícola dos EUA decorre do fato de os demais programas de apoio ao produtor reduzirem substancialmente o valor atribuído à redução de risco proporcionado pelo seguro agrícola.

Por fim, uma das questões mais sensíveis do modelo norte-americano refere-se à sua determinação de universalidade de acesso, pela qual a nenhum produtor rural elegível ao programa pode ser negado o direito ao seguro agrícola em qualquer um dos estados por uma seguradora que lá atue, por pior risco que ele possa representar. Sendo assim, como conciliar um objetivo de acessibilidade universal com eficiência econômica? Como garantir sustentabilidade atuarial de companhias seguradoras privadas, de forma a que possam manter-se e competir no mercado segurador? Tal fato torna-se ainda mais grave ao se considerar que é o próprio governo, por meio da RMA, que tem a responsabilidade pela precificação das apólices de seguro agrícola em todo os EUA. A resposta parece encontrar-se no Acordo Padrão de Resseguro (SRA), que constitui o coração da parceria envolvendo governo e setor privado. Como exposto anteriormente (item 4.2), pelos termos do Acordo, as seguradoras podem direcionar as apólices de maior risco para o Assigned Risk Fund, que oferece a elas condições extremamente vantajosas em caso

\footnotetext{
${ }^{19}$ Para essa análise, os autores utilizaram uma metodologia de mensuração denominada Certainty Equivalent (Equivalente-certeza).
} 
de perdas. Esse tipo de acordo não oferece qualquer incentivo a uma política de eficiência e precaução na subscrição de riscos. Além de proporcionar lucros excessivos às seguradoras, ele impõe ainda um ônus adicional aos contribuintes, que não só pagam os subsídios e os custos do programa, mas também os prejuízos causados por uma administração de riscos menos eficiente do que ocorreria sob condições normais.

A respeito do SRA, Ker (2001), baseando-se em cálculos de Miranda (2001), estima que o subsídio implícito na política de resseguro seja de $20 \%$. Da mesma forma, Vedenov et al. (2004), em uma análise econômica do SRA, afirmam que no período entre 1997 e 2001 as seguradoras signatárias do SRA obtiveram ganhos líquidos de cerca de US\$ 1,5 bilhão, equivalente a $16,6 \%$ do valor dos prêmios e que tais lucros teriam, inclusive, despertado críticas por parte de agências governamentais de controle. Os autores concluem que os termos do resseguro proporcionado pelo SRA resultaram em maior valor e menor variação nos lucros das seguradoras, representando assim um incentivo à participação dessas no programa de seguro agrícola norte-americano. Ainda segundo os autores, mesmo em nível regional, a existência do Acordo faz com que o seguro agrícola seja lucrativo na maioria dos estados e que as seguradoras se disponham a segurar produtores e culturas de maior risco, dada a possibilidade de transferência deste à FCIC/RMA.

\section{Conclusões}

O mercado de seguros talvez se constitua em um dos mercados no qual a prevalência das informações assimétricas seja determinante na inibição à sua formação e ao seu pleno desenvolvimento. Os problemas decorrentes da seleção adversa e do risco moral parecem ser ainda mais relevantes para o mercado de seguro agrícola, que também padece com os elevados custos de entrada e operacional, além do risco sistêmico.

Essas características têm inibido o desenvolvimento satisfatório deste ramo e fazem com que na maioria dos países onde o seguro agrícola se encontra mais desenvolvido seja comum a presença do Estado, atuando diretamente como segurador e/ou subsidiando prêmios e despesas operacionais de seguradoras, de forma a aumentar a atratividade para seguradoras e produtores rurais. No entanto, essa possibilidade pressupõe uma forte capacidade fiscal, condição esta encontrada, na maioria das vezes, apenas em países desenvolvidos. 
Este é justamente o caso dos EUA, aonde o desenvolvimento do seguro agrícola vem-se dando calcado no estabelecimento de um generoso acordo de resseguro (SRA), e, principalmente, nos elevados percentuais de subsídio ao prêmio e às despesas operacionais das seguradoras, que demandam considerável montante de gastos públicos com o programa. Diversos autores questionam a eficiência da política de subsídio ao prêmio, uma vez que, para eles, a demanda por seguro caracteriza-se claramente como inelástica. Outros afirmam que essa política traz consigo uma grande dose de ineficiência, com a sociedade pagando para o produtor rural assumir um risco adicional que ele normalmente não assumiria.

A experiência com o programa norte-americano de subsídio ao prêmio parece demonstrar que ele altera a decisão de plantio dos agricultores. No entanto, os efeitos, além de modestos, dependem também da influência de outras variáveis. Para a maioria dos autores, os impactos sobre a área plantada em nível nacional são estatisticamente insignificantes. Ressalte-se, porém, que essa constatação esconde impactos relevantes do ponto de vista regional e de culturas específicas.

A análise da experiência norte-americana deixa claro que o desenvolvimento do seguro agrícola além de dispendioso é um processo de longo prazo, requerendo ainda diversas outras ações por parte de governos e iniciativa privada. Assim, países que pretendem fazer uso desse instrumento em suas políticas agrícolas, como é o caso do Brasil, devem estar atentos a esses resultados e aos problemas gerados ou ampliados por sua utilização de forma mais generalizada.

\section{Referências Bibliográficas}

AAFC - AGRICULTURE AND AGRI-FOOD CANADA. The Federal-Provincial Crop Insurance Program. An Integrated Environmental-Economic Assessment; Relatório; Ottawa, Canada; 1998.

AZEVEDO-FILHO A.; Seguro Agrícola no Brasil: evolução e perspectivas. Congresso de Tecnologia da Soja no Mercado Global. Cuiabá/MS. 2000. Anais. Fundação Mato Grosso. 2000. P.95-105.

AZEVEDO-FILHO A.; Seguros fundamentados em índices de produtividade e renda agrícola regional como instrumentos para 
administração de riscos no Brasil. Projeto FAPESP/CNPq. Relatório de pesquisa - subprojeto 8. Piracicaba. Outubro de 2001.

BABCOCK, B.A., HENESSY, D.A.; Input Demand under Yield and Revenue Insurance. American Journal of Agricultural Economics. USA. Vol. № 78, maio, 1996, p. 416-427.

BARNETT, B.J.; The U.S. Federal Crop Insurance Program. Canadian Journal of Agricultural Economics. Vol. 48, № 4, 2000, p. 539-551

EISENHAUER, J.G.; Risk Aversion and the Willingness to Pay for Insurance: A Cautionary Discussion of Adverse Selection. Washington D.C. USA. Risk Management and Insurance Review, Vol. 7, № 2, 2004, p. 165-175

GLAUBER, J. W.; Crop Insurance Reconsidered. American Journal of Agricultural Economics. USA. Vol. 86, № 5, 2004, p. 1179-1195

GLAUBER, J.W.; COLLINS, K.J.; Crop Inurance, Disaster Assistance and the Role of the Federal Government in Providing Catastrophic Risk Protection. Agricultural Finance Review. № 69, 2002, p.81-102.

GOODWIN, B.K.; An Empirical Analysis of the Demand for Multiple Peril Crop Insurance. American Journal of Agricultural Economics. USA. Vol. 75, № 2, maio, 1993, p. 425-434.

GOODWIN, B.K.; Problems with Market Insurance in Agriculture. American Journal of Agricultural Economics. EUA. Vol. 83, № 3, agosto, 2001, p. 643-649.

GOODWIN, B.K.; VENDEEVER, M.L.; DEAL J.; An Empirical Analysis of Acreage Effects of Participation in the Federal Crop Insurance Program." American Journal of Agricultural Economics. USA. Vol. 86, № 4, novembro, 2004

GRAY, A.G., BOEHLJE. M.D., GLOY, B.A., SLINSKY, S.P. How U.S. Farm Programs and Crop Revenue Insurance Affect Returns to Farm Land. Washington, DC, USA. Review of Agricultural Economics. Vol. 26. № 3. 2004, p. 238-253.

HOROWITZ, J.K.; LICHTENBURG, E.; Insurance, Moral Hazard, and Chemical Use in Agriculture. American Journal of Agricultural Economics. USA. Vol. 75, № 4, novembro, 1993, p. 926-935 
KER, A.P.; Private Insurance Company Involvement in the U.S. Crop Insurance Program. Canadian Journal of Agricultural Economics. Vol. 49. 2001. p. 557-566

MAKKI, S., SOMWARU A. Farmers' Participation in Crop Insurance Markets: Creating the Right Incentives. Washington, DC, USA. American Journal of Agricultural Economics. № 83. Vol. 3. 2001, p. 662-667.

MISHRA, Ashok K.; NIMON, R. Wesley; EL-OSTA, Hisham S. Is moral hazard good for the environment? Revenue insurance and chemical input use. Washington, DC, USA. Journal of Environmental Management, no 74 , 2005 , p. 11 a 20.

OSAKI, V. A.; Métodos Atuariais Aplicados à Determinação da Taxa de Prêmio de Contratos de Seguro Agrícola: um estudo de caso. Piracicaba, SP, 2005. Tese (Doutorado). Escola Superior de Agricultura Luiz de Queiroz, Universidade de São Paulo.

PINDYCK, R. e RUBINFELD, D. Microeconomia. São Paulo. Editora Prentice Hall. 2002.

SKEES, J. R.; Agricultural Risk Management or Income Enhancement? Washington D.C. USA. Regulation, Vol. 22, № 1, 1999(a), p. 35-43

SKEES, J. R.; Policy Implications of Income Insurance: Lessons learned from the $U S$ and Canada. Documento preparado para o Encontro Anual da Associação Européia de Economia Agrícola. Varsóvia, Polônia. Agosto de 1999(b).

SOUSA, I.J.M.; Seguro agrícola induz a investimentos em tecnologia. Seguros \& Riscos. São Paulo. Vol. 5, no 54. Agosto, 1990(a), p. 11-12.

SOUSA, I.J.M.; Ampliar o seguro rural é o objetivo da Cosesp. Seguros \& Riscos. São Paulo. Vol. 5, no 54. Agosto, 1990(b), p. 13-16.

STIGLITZ, J. e WALSH, C. Introdução à Microeconomia. Rio de Janeiro. Editora Campus. 2003.

U.S. DEPARTMENT OF AGRICULTURE. RISK MANAGEMENT AGENCY. Standard Reinsurance Agreement. 2005. Disponível em > http://www.rma.usda.gov. Acesso em 13.02.2006. 
VEDENOV, D.V., MIRANDA M.J.; DISMUKES, R.; GLAUBER, J.W. Economic Analysis of the Standard Reinsurance Agreement. Agricultural Finance Review. Vol. 64, № 2. EUA. 2004.

WENNER, M., ARIAS D.; Agricultural Insurance in Latin America: Where are we? Banco Inter-americano de Desenvolvimento. Washington. EUA. Estudo de Caso. 2003.

YOUNG, C.E.; VANDEVEER; M.L.; SCHNEPF R.D.; Production and Price Impacts of U.S. Crop Insurance Programs. Washington D.C. USA. American Journal of Agricultural Economics, no 83, Vol. 5, 2001, p. 1196-1203. 